\title{
BMJ Open Birth defects surveillance after assisted reproductive technology in Beijing: a whole of population-based cohort study
}

\author{
Lu Zhang (D) , Wen Zhang, Hongyan Xu, Kaibo Liu
}

To cite: Zhang L, Zhang W, $\mathrm{Xu} \mathrm{H}$, et al. Birth defects surveillance after assisted reproductive technology in Beijing: a whole of populationbased cohort study. BMJ Open 2021;11:e044385. doi:10.1136/ bmjopen-2020-044385

- Prepublication history for this paper is available online. To view these files, please visit the journal online (http://dx.doi org/10.1136/bmjopen-2020044385).

Received 03 September 2020 Accepted 13 May 2021

Check for updates

(C) Author(s) (or their employer(s)) 2021. Re-use permitted under CC BY-NC. No commercial re-use. See rights and permissions. Published by BMJ.

Department of Perinatal Health Care, Capital Medical University Beijing Obstetrics and Gynecology Hospital, Beijing, China

Correspondence to

Dr Kaibo Liu;

kaiboliu_beijing@hotmail.com

\section{ABSTRACT}

Objectives To compare the differences in the prevalence of birth defects among offspring conceived by assisted reproductive technology (ART) and conceived spontaneously (non-ART), and assess the contribution of ART to birth defects.

Design A population-based retrospective cohort study. Setting Beijing.

Participants Pregnant women whose expected date of childbirth was verified as occurring between 0ctober 2014 and September 2015, and were registered on the Beijing Maternal and Child Health Information Network System, were the recorded pregnancy outcomes. 2699 ART offspring and 191368 non-ART offspring (live births, stillbirths and medical terminations) were included in our study.

Interventions None.

Outcome measures Risk ratios (RR) for birth defects were calculated among ART conceptions and non-ART conceptions with confounding factors by using logistic regression models.

Results 194067 offspring were included in the present study, and 2699 (1.4\%) were conceived using ART. Among all the births, the prevalence of any birth defect in the ART offspring (5.5\%) was significantly higher than in the non-ART offspring (3.8\%) (crude RR, 1.49, 95\% Cl 1.26 to 1.76). After adjusting for confounding factors, ART use was still associated with an increased risk of any birth defect (5.4\% vs 3.5\% in ART and non-ART group, adjusted $\mathrm{RR}$ (aRR), $1.43,95 \% \mathrm{Cl} 1.08$ to 1.90 ), especially for chromosomal abnormalities $(0.5 \%$ vs $0.2 \%$ in ART and non-ART group, aRR, 3.11, 95\% Cl 1.28 to 7.58 ), in singleton births to mothers $<35$ years. Circulatory system malformations and musculoskeletal system malformations were observed to have a non-significant increase in offspring conceived by ART. However, the associations between ART and birth defects were not detected in multiple births or mothers $\geq 35$ years.

Conclusions This study confirmed a small but significant association between ART and birth defects. However, the risk tends to be non-significant under the conditions of advanced maternal age or multiple pregnancies.

\section{INTRODUCTION}

In 1978, the world's first infant conceived with assisted reproductive technology (ART) was born in the UK. ${ }^{12}$ According to published reports, almost 1.5 million cycles of in vitro

\section{Strengths and limitations of this study}

- We used a whole of population-based surveillance data between 2014 and 2016 in Beijing to analyse the relationship between assisted reproductive technology (ART) and birth defects.

- Rich demographic and clinical information collected by the Beijing Maternal and Child Health Information Network System allowed a thorough adjustment for confounding, assessment of mediation and subgroup analysis.

- The ART information was self-reported by the pregnant women, and the under-reporting of ART experience maybe exist.

- The specific classification of ART at an individual level such as intrauterine insemination, in vitro fertilisation, intracytoplasmic sperm injection or preimplantation genetic testing was not available.

fertilisation (IVF) are performed annually, resulting in 350000 offspring worldwide. ${ }^{34}$ Mainland China's first successful ART-IVF conception occurred in Beijing in 1988. ${ }^{5}$ Fertility treatments including intrauterine insemination (IUI) and all the procedures for ART - IVF, intracytoplasmic sperm injection (ICSI), fresh embryo transfer, frozen embryo transfer (FET), in vitro maturation, elective single embryo transfer, blastocyst embryo transfer, egg donation and preimplantation genetic testing (PGT) - are all permitted by the Chinese National Health Commission and are available to patients. ${ }^{6}$ Between 2013 and 2015, over 25000 IUI cycles, 65000 (IVF-ICSI) oocyte aspirations, and 76000 embryo transfers were reported from the IVF centres in Beijing. ${ }^{6}$

Although ART has been successful in solving infertility problems, there have always been concerns about whether the process-involving superovulation, in vitro culture, fresh or frozen-thawed transfers use of cleavage stage embryos or blastocysts, heterologous IVF with oocyte donation, PGT and other micromanipulationswould interfere with the cell proliferation, 
differentiation and growth of the embryos. ${ }^{7-10}$ Initial cohort studies with small sample sizes showed that ARTconceived infants seemed to be healthy. ${ }^{11}$ However, subsequent case-control studies and meta-analysis suggested that ART-based conceptions had increased risks for birth defects compared with non-ART conceptions, particularly among singleton pregnancies. ${ }^{12-17}$ A potential increase in cardiovascular, musculoskeletal, urogenital and gastrointestinal system malformations $^{18-20}$ was observed in offspring conceived using ART.

With the expanded use of ART in China, some largesample studies using data from IVF centres only, or limited-linked resources, were performed in recent years. ${ }^{6}{ }^{21-26}$ However, the accuracy of the results and the consequent application of the conclusions drawn were restricted by the limited study population. ${ }^{27}$ In the present study, for the first time, we used a whole of population-based surveillance data between 2014 and 2016 from the Beijing Maternal and Child Health Information Network System (BMCHINS) to assess the prevalence of birth defects among ART-conceived offspring, compared with non-ART conceptions. Thus, we examined the potential risk of birth defects associated with ART in Beijing, China.

\section{MATERIALS AND METHODS}

\section{Study design and data sources}

We performed a population-based retrospective cohort study using surveillance data from 2014 to 2016, from the BMCHINS, which was officially established to collect information regarding all pregnant women and their offspring, from all the community health service centres, midwifery agencies and children's hospitals in Beijing. Data quality assurance is carried out every year with reports being presented to the ministry of government administration.

The information regarding ART and basic maternal information-including maternal age, prepregnancy body mass index (BMI), residence, ethnicity, education, medical and reproductive history-were collected at a pregnant woman's first visit (usually before 13 weeks gestation) to the community health service centre. The health status, medical complications, examination and treatment received during the pregnancy, fetal screening and diagnoses were recorded and updated at every patient visit to the midwifery agencies. Pregnancy outcomes, including live birth, miscarriage (not included in our study population), stillbirth (after 20 gestational weeks) and medical termination of pregnancy, were also recorded on their electronic medical records at the end of pregnancy.

Congenital abnormalities (birth defects) detected in pregnancy (after 13 gestational weeks) or during the infancy period (within 1 year after birth) were reported by obstetricians or paediatricians to the birth defects unit on BMCHINS with the use of a standardised congenital abnormality form. The diagnoses of birth defects were confirmed by cross-referencing of medical records and coded according to the modification of the International Classification of Diseases, 10th revision (ICD-10), including structural abnormalities, biochemical abnormalities and chromosomal or otherwise genetic abnormalities.

\section{Statistical analysis}

We used the statistical software SPSS V.18.0 (SPSS) for Windows for all analyses. The proportional distributions of sociodemographic characteristics between ART and nonART offspring were compared using the Pearson $\chi^{2}$ tests (two tailed, significance level $=0.05$ ). The variables included plurality, sex of the offspring, maternal age, residence, ethnicity, education, parity, prepregnancy BMI (categorised as per the WHO guideline for Asian populations ${ }^{28}$ ), history of adverse pregnancy outcomes, history of infertility, medical complications in pregnancy (preexisting hypertension, pregnancy-induced hypertension, preexisting diabetes, gestational diabetes, anaemia), maternal folic acid supplementation, first visit to a doctor, and visits to the doctor during pregnancy. Risk ratios were calculated with $95 \%$ CIs and Pearson $\chi^{2}$ analysis, by comparing the incidences of birth defects and the subcategories of birth defects between the two groups. The adjusted analysis used a logistic regression equation, including apriori confounding factors of maternal age (categorised in 5-year groups, in most subcategory analyses of birth defects), parity (first, and second or above), prepregnancy BMI (underweight or normal, overweight and obesity), maternal residence (Beijing and other places), diabetes, hypertension, anaemia and folic acid supplementation (not taking, not regular and regular; only in the model for nervous system malformations analysis). For all comparisons, any birth defect, chromosomal abnormality and Down's syndrome were analysed with stratification into maternal age $<35$ years and $\geq 35$ years. We also conducted a subgroup analysis for singleton and multiple births. Multiple pregnancies included twins and triplets in our study.

\section{Patient and public involvement}

Patients or the public were not involved in the design, or conduct, or reporting or dissemination of our study.

\section{RESULTS}

A total of 206079 pregnant women whose expected date of childbirth was verified to be between October 2014 and September 2015 were registered on BMCHINS. Among them, 2131 ART-conceived pregnant women and 193 271 non-ART pregnant women had recorded pregnancy outcomes (live births, stillbirths, miscarriage and termination of pregnancy). Ultimately, except for those miscarriages, 2699 (1.4\%) ART offspring and 191368 non-ART offspring were included in our retrospective cohort study (figure 1).

\section{Sociodemographic characteristics}

The descriptive statistics of the 194067 offspring by mode of conception are shown in table 1. Compared with the 
non-ART group, offspring conceived using ART had higher frequencies of multiple births. The ART mothers had higher frequencies of advanced age, native residence, primipara delivery, being overweight or obese, a history of adverse pregnancy outcomes or infertility and medical complications in pregnancy. They were more willing to follow the doctor's advice, including taking folic acid as recommended $(400 \mu \mathrm{g}$ folic acid per day, beginning 3 months before becoming pregnant and through the first 12 weeks of the pregnancy), and initiating and maintaining earlier and regular visits to the doctor. However, there was no difference in the distributions of sex of the offspring, maternal ethnicity, and maternal education between the two groups.

\section{Risk of birth defects associated with ART}

Among all births, the prevalence of birth defects in the ART offspring (5.5\%, $\mathrm{n}=149)$ was significantly higher than that in non-ART offspring $(3.8 \%, \mathrm{n}=7233)$ (crude RR (cRR), 1.49; 95\% CI 1.26 to 1.76). In the stratified analysis based on maternal age, ART was associated with an increased risk of any birth defect in births to mothers $<35$ years $(5.3 \%$ vs $3.6 \%$ in ART and non-ART group, adjusted risk ratio (aRR), 1.39; 95\% CI 1.12 to 1.71 ), but not to mothers aged $\geq 35$ years $(6.1 \%$ vs $5.4 \%$ in ART and non-ART group, aRR, $0.98 ; 95 \%$ CI 0.73 to 1.33 ). When we stratified by plurality (singletons vs multiples), the multivariate analysis showed that the risk was still significantly different between ART use and non-ART to mothers $<35$ years in singleton births $(5.4 \%$ vs $3.5 \%$ in ART and non-ART group, aRR 1.43 ; 95\% CI, 1.08 to 1.90 ), but not in multiple births $(5.1 \%$ vs $6.3 \%$ in ART and non-ART group, aRR, 0.79 ; $95 \%$ CI 0.56 to 1.10 ) (table 2).

On analysis of the subcategories of birth defects among all the births, the results showed an increased risk for circulatory system malformations $(2.0 \%$ vs $1.4 \%$ in ART and non-ART group, cRR, 1.40; 95\% CI 1.06 to 1.84 ), musculoskeletal system malformations and deformations $(0.9 \%$ vs $0.6 \%$ in ART and non-ART group, cRR, $1.59 ; 95 \%$ CI 1.06 to 2.38), multiple defects $(0.9 \%$ vs $0.5 \%$ in ART and non-ART group, cRR, $1.63 ; 95 \%$ CI 1.08 to 2.47$)$ and other malformations $(0.7 \%$ vs $0.4 \%$ in ART and non-ART group, cRR, 1.82; $95 \%$ CI 1.14 to 2.90) in the ART-use group. However, these associations were not significant after adjusting for confounding factors. For singleton births, the prevalence of circulatory system malformations (2.3\% vs $1.4 \%$ in ART and

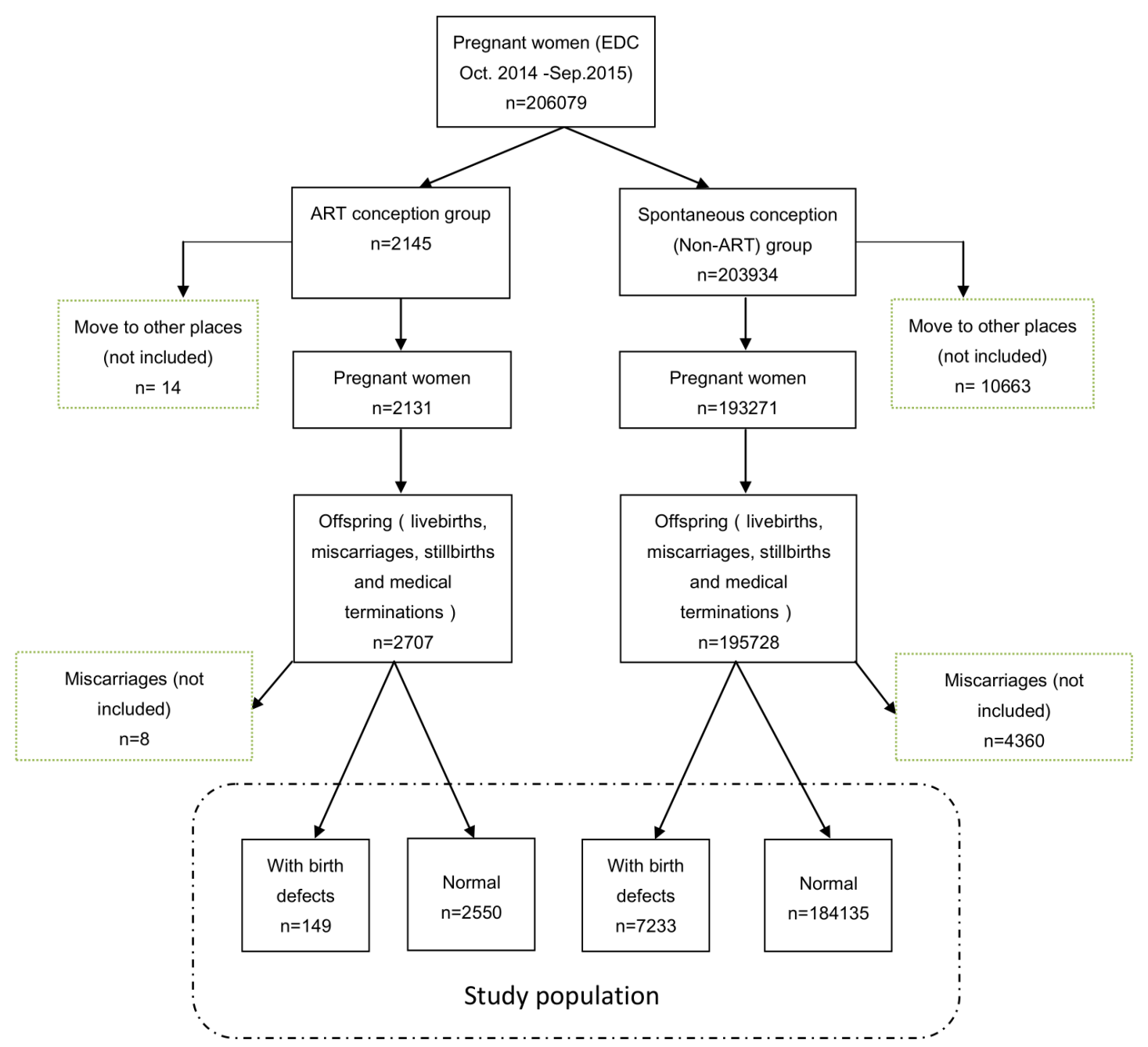

Figure 1 Study population. ART, assisted reproductive technology; EDC, expected date of childbirth. 
Table 1 Characteristics of offspring, by mode of conception

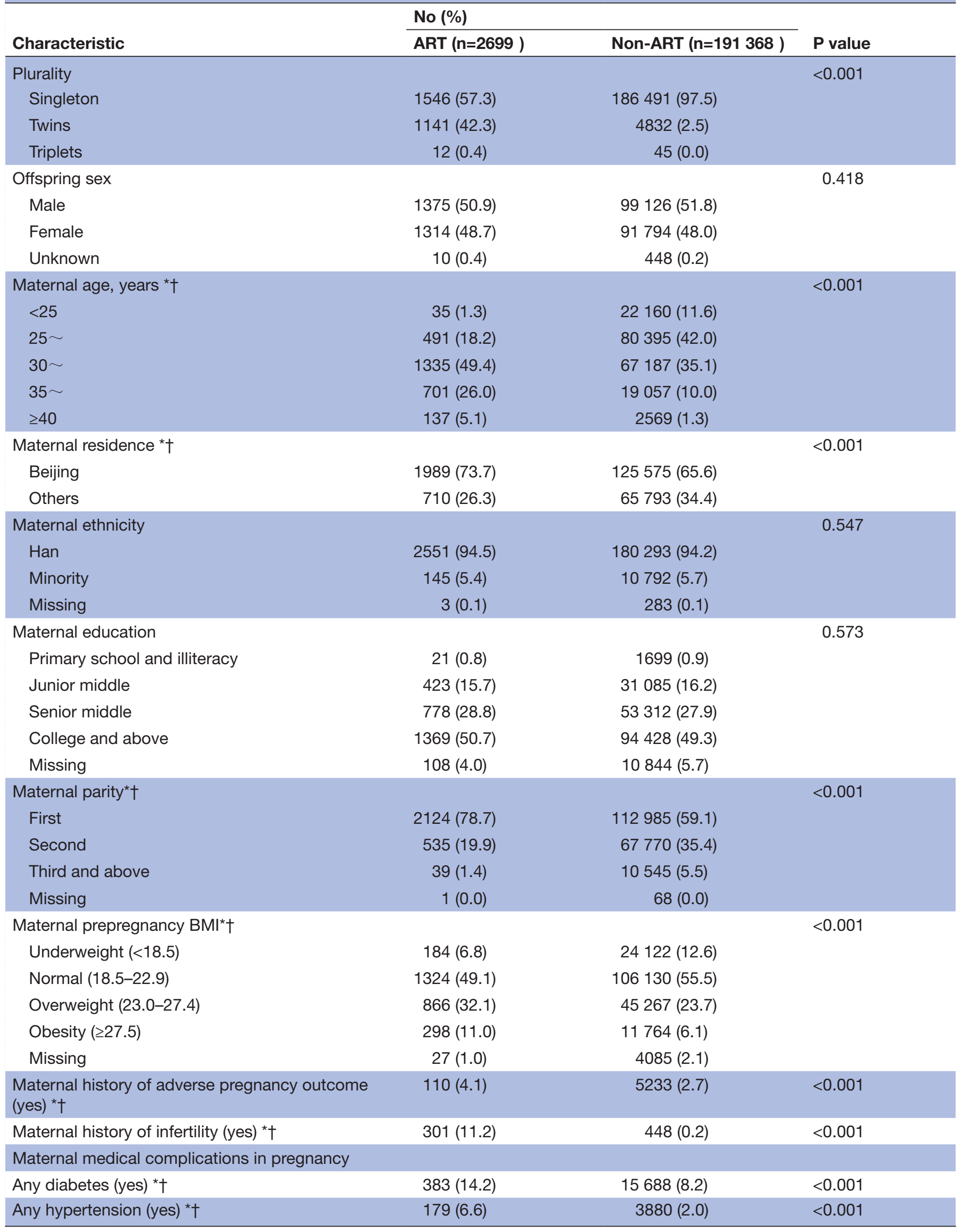


Table 1 Continued

\begin{tabular}{|c|c|c|c|}
\hline \multirow[b]{2}{*}{ Characteristic } & \multicolumn{2}{|l|}{ No (\%) } & \multirow[b]{2}{*}{ P value } \\
\hline & ART (n=2699) & Non-ART $(n=191368)$ & \\
\hline Anaemia (yes)† & $169(6.3)$ & $10175(5.3)$ & 0.030 \\
\hline No & $82(3.0)$ & $15083(7.9)$ & \\
\hline Yes but not regularly & $290(10.7)$ & $41217(21.5)$ & \\
\hline Missing & $5(0.2)$ & $635(0.3)$ & \\
\hline Maternal first visit to a doctor ${ }^{\star} \dagger$ & & & $<0.001$ \\
\hline First trimester & $2357(87.3)$ & $135786(71.0)$ & \\
\hline Second trimester & $275(10.2)$ & $41741(21.8)$ & \\
\hline$>4$ times & $2529(93.7)$ & $168912(88.3)$ & \\
\hline $0-4$ times & $53(2.0)$ & $8316(4.3)$ & \\
\hline Missing & $117(4.3)$ & $14140(7.4)$ & \\
\hline
\end{tabular}

$P$ value calculated without the condition of unknown data.

${ }^{*} \mathrm{P}<0.05$ in single offspring when comparing ART group and non-ART group;. †P $<0.05$ in multiple offspring when comparing ART group and non-ART group;

$\mathrm{ART}$, assisted reproductive technology; BMI, body mass index.

non-ART group, cRR, 1.65 ; $95 \%$ CI 1.18 to 2.31 ) and chromosomal abnormalities $(0.5 \%$ vs $0.2 \%$ in mothers $<35$ years ART and non-ART group, cRR, 2.96; 95\% CI 1.22 to 7.19 ) ( $1.7 \%$ vs $0.8 \%$ in mothers $\geq 35$ years ART and non-ART group, cRR, 2.05; 95\% CI 1.04 to 4.03 ) in ART births were significantly higher than in nonART births. Nevertheless, the prevalence of Down's syndrome was not higher in the ART births $(0.1 \%$ vs $0.1 \%$ in mothers $<35$ years ART and non-ART group; cRR, $1.31 ; 95 \%$ CI 0.18 to 9.39$)(0.6 \%$ vs $0.4 \%$ in mothers $\geq 35$ years ART and non-ART group; cRR, 1.40 ; 95\% CI 0.44 to 4.43 ). After adjusting for confounding factors, only the risk of chromosomal abnormalities was still statistically significant in births to mothers $<35$ years in the ART group $(0.5 \%$ vs $0.2 \%$ in ART and non-ART group, aRR 3.11; $95 \%$ CI 1.28 to 7.58 ). When the study population was restricted to multiple births, no significant associations were detected (table 2).

\section{DISCUSSION}

In this population-based cohort study, ART contributed to approximately $1.4 \%$ of the total births in Beijing. This proportion was close to the estimated ART-associated births in China by some researchers $(1 \%-2 \%),{ }^{29}$ but is lower than the percentage reported in a hospital-based cohort study from Shanghai by Min Yang $(2.22 \%),{ }^{23}$ with no more published data being available for further reference. In contrast to the other countries, the proportion is similar to the United States $(1.4 \%-1.8 \%),{ }^{19}{ }^{30-32}$ but is lower than in Australia (2.0\%), ${ }^{18}$ Italy $(2.5 \%)^{33}$ and Japan $(3.6 \%) .{ }^{34}$ In accordance with previous studies and meta-analyses, ${ }^{1819}$ 35-39 including several Chinese big-data studies, ${ }^{2324}$ ART mothers tended to be older, overweight or obese, were more likely to have a history of adverse pregnancy outcomes, and had a greater incidence of multiple conceptions and chronic conditions during the pregnancy.

\section{Risk of birth defects associated with ART}

Our study confirms the results of previous studies, with about a $30 \%-40 \%$ increase in the frequency of birth defects among offspring born after ART. However, the association tends to be non-significant in patients with advanced maternal age, or multiple conceptions.

For all births, the incidence of birth defects in our study was $3.8 \%$, which is close to the reported prevalence of birth defects in China (4\%-6\%). ${ }^{40} 41$ In the stratified analysis for singleton births, the risk of birth defects in the ART group (5.9\%) was significantly higher than in the non-ART group $(3.7 \%)$. This result was compatible with previous findings. ${ }^{18} 1935-39$ In the stratified analysis for multiple births, however, the risk of birth defects in the ART group $(5.0 \%)$ did not seem to be higher than in the non-ART group $(6.3 \%)$, in fact it was lower, with no statistical difference being found in the values. This association, as previous studies confirmed, might be partly due to more dizygotic twins (owing to insertion of multiple embryos) in ART conceptions than in the nonART conceptions. Research on twin pregnancies shows that dizygotic twins are at a lower risk of birth defects 
$\overline{\bar{\alpha}}$

总

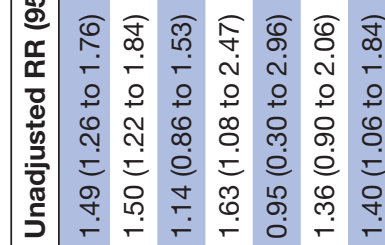

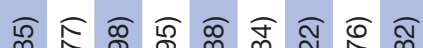

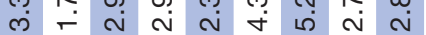
우 우 0 우 0 우 ๗ $\infty$ 으

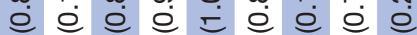
๒
䓂

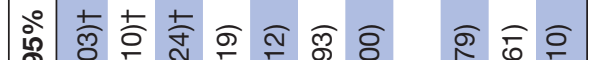
ब 品 ซ 苟 é é é é é é é é

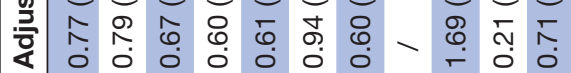

$\overline{\bar{c}}$

응

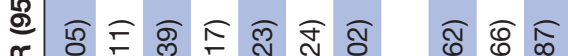
吕

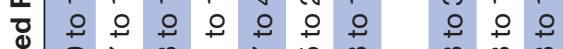

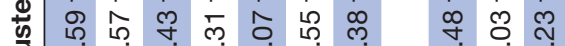
高 仓ீ ฐ

อ

5 ल

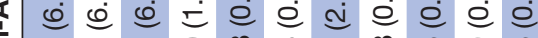
ż $\frac{n}{\frac{5}{0}}$ 능

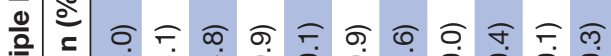

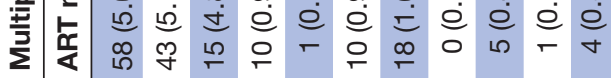

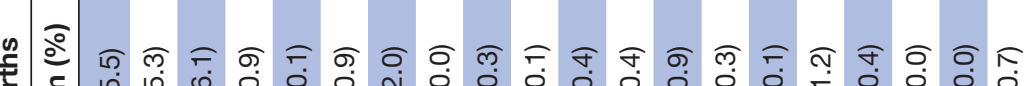

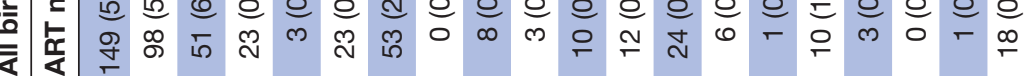

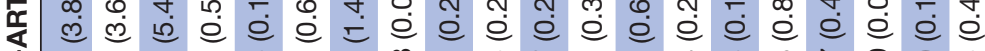
ż

บิ

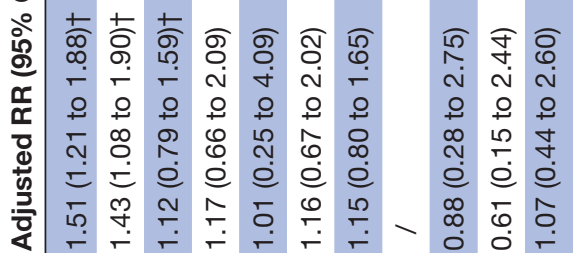

它

倠

o

की

인

$\stackrel{\infty}{\sigma}$

으음

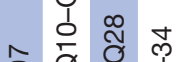

它

ํํำ

ธิ

๖े

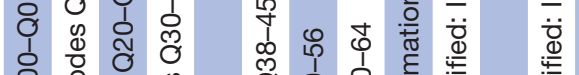

8000

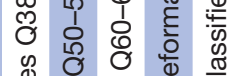

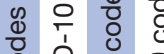

잉

过

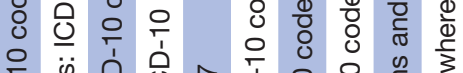

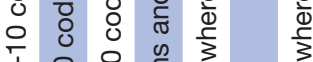

它

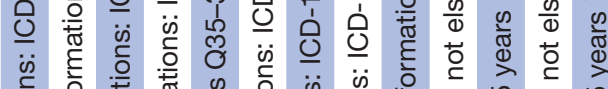

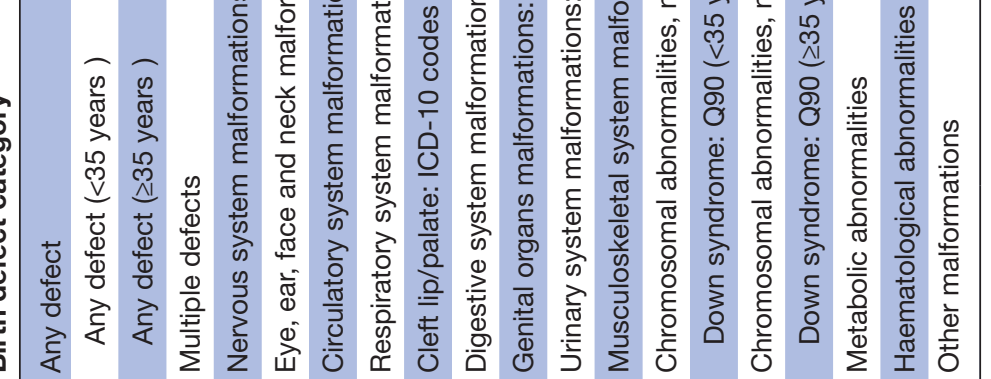

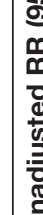

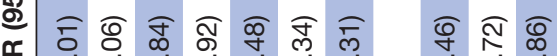

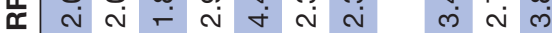

힝ㅇㅇㅇㅇㅇㅇㅇㅇㅇㅇㅇㅇㅇㅇㅇ

ஸे

- ¿

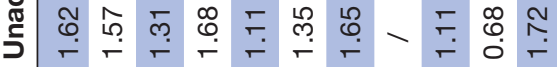

ఏ

เ

एँ

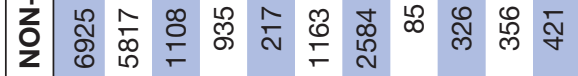

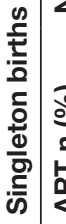

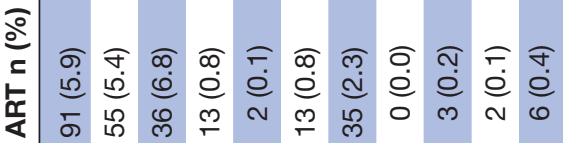

$\frac{3}{3}$

๑

을.

ㅇํㄹ

옥

을.

กั

N

ㅁ

$\stackrel{\circ}{\mathbb{D}}$ 


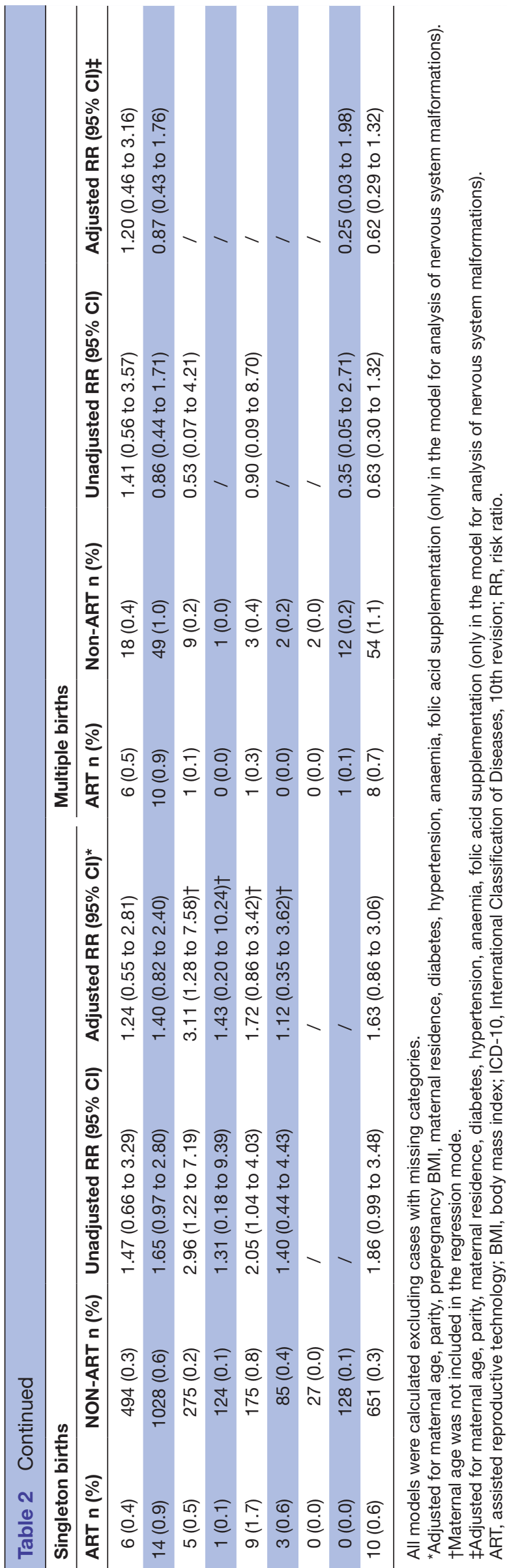

than monozygotic twins, ${ }^{42} 43$ this being attributed to potential errors in the zygotic division or vascular interchange of monozygotic twins. ${ }^{445}$

When stratified by maternal age, the risk of birth defects in the ART group was significantly higher than in the nonART group only in mothers aged $<35$ years, but not in mothers aged $\geq 35$ years. The potential explanation for the non-significant association between ART and birth defects among mothers aged $\geq 35$ years, may be due to the broadly lower fertility of older mothers. ${ }^{46}$ As widely accepted, maternal age is an independent risk factor for women's fecundity and their pregnancy outcomes, including birth defects. The lower fertility and higher incidence of birth defects occurred among older mothers not only in ART conceptions but also in non-ART conceptions. Thus, although the prevalence of birth defects in ART conceptions was higher than in non-ART conceptions, the difference tended to be non-significant among mothers aged $\geq 35$ years (the stronger risk factor for birth defects). However, this non-statistical association between ART and birth defects among older mothers was not obtained in previous studies. ${ }^{12-172324}$ The possible reason may be attributed to the differing study populations or differing fertility and health status. Several studies by IVF centres have shown that Chinese patients had more secondary infertility than reported in other countries, ${ }^{6}$ which possibly means fewer embryo problems in the Chinese ART population, and a non-significant difference in the fertility status between the ART and non-ART populations. Further research and data are needed to elucidate the causal mechanisms.

Notably, the subgroup analysis of birth defects in our study documented a significantly increased prevalence of chromosomal abnormalities among singleton ART births to mothers $<35$ years of age. The result might be explained by the more serious underlying health issues and the poor-quality embryos in young women undergoing ART (the critical reason for ART), although this positive result was not obtained in other studies. ${ }^{19}{ }^{24} 33$ Another explanation may be due to the good compliance of ART mothers with their doctors. They appeared to be more concerned about their own health and that of their offspring, visiting doctors early and more often, and receiving more prenatal screening. Thus, birth defects in the ART group might be more frequently detected than in the non-ART group, for example, microdeletion or microduplication syndromes, etc.

Additionally, we found that the prevalence of circulatory system malformations, musculoskeletal system malformations, and multiple defects increased in the ART group, although it tended to be statistically non-significant after considering potential confounding factors. The results were compatible with previous findings of the high incidence of these abnormalities among ART births. ${ }^{18-20} 334748$ Previous study showed that increased risk of circulatory system malformations may be a consequence of early placental dysfunction with lower pregnancy-associated plasma protein A, lower placenta growth factors and higher free $\beta$-human chorionic gonadotropin concentrations in the 
first trimester among IVF/ICSI pregnancies. ${ }^{20}{ }^{49-51}$ More data were needed for further research and confirmation on the mechanism of increased musculoskeletal system malformations, and multiple defects among ART births.

\section{Strengths and limitations}

Our study had several strengths. First, we used a whole of population based surveillance data to analyse the relationship between ART and birth defects in Beijing. The study sample was based on the entire population of Beijing city. Since we had a 100\% capture for hospital and home births in Beijing, our study was free from any bias caused by selective inclusion of births. Second, birth defects in our study were detected from 13 weeks of pregnancy up to a child's first birthday, and defined as per the ICD-10 code, so that the birth defect data could be efficiently captured, and were less likely to be under-reported or misclassified. Third, the data quality of BMCHINS has been under strict control and is considered to be high. Rich demographic and clinical information collected by the BMCHINS allowed a thorough adjustment for confounding, assessment of mediation and subgroup analysis, such as the maternal prepregnancy BMI, adverse pregnancy outcome history, and infertility history.

However, there are several limitations in our study as well. First, the ART information was self-reported by the pregnant women. Although ART mothers are generally thought to be willing to announce their ART information to the doctors for better medical care, the underreporting of ART experience maybe still exist. There might be misclassification within the data such that some ART-conceived offspring are labelled as unexposed. By comparing ART births to 'non-ART' births (ART mixed), effect estimates are likely biased to the null. Second, the specific classification of ART at an individual level such as IUI, IVF, ICSI, fresh or FET and PGT was not available. Studies showed that uterine perfusion and early fetal growth were improved in IVF or ICSI pregnancies conceived after FET as compared with fresh embryo transfer, and this may be highly relevant for organogenesis and embryonic development. ${ }^{78}$ PGT aims at avoiding transfer of 'abnormal' embryos to improve the probability of conceiving a viable pregnancy theoretically, but there is still a possibility that the embryo biopsy procedure itself may negatively affect the viability of the embryo and lower the probability of pregnancy. Nevertheless, the differences in the incidence of birth defects between IVF and ICSI, fresh and FET, IVF with PGT and IVF without PGT, were not significantly different in most studies. ${ }^{6} 91016192126{ }^{52}$ Finally, paternal information as a confounding factor was not included in our study, although it was usually thought to have little impact on the occurrence of birth defects. ${ }^{5354}$

\section{CONCLUSIONS}

This study confirmed a small but significant association between ART and birth defects. However, the risks tended to be non-significant with advanced maternal age and multiple pregnancies. Our result indicated that the underlying subfertility and/or the high proportion of multiple births among ART pregnancies seemed to contribute critical roles in the higher prevalence of birth defects than ART procedures. As previous study confirmed, subfertility and multiple births affect the associations between ART and several birth defects, with subfertility explaining a substantial portion and multiple births explaining about $30 \%$ of the relative effect of ART on some birth defects. ${ }^{556}$ Hence, couples experiencing problems with infertility or other health issues should be fully assessed and counselled, during the conception period and while pursuing ART.

Contributors LZ, WZ, HX and KL contributed to the conception and design of the study. LZ, WZ and HX contributed to data collection. LZ led the data analysis of the data. LZ, WZ, HX and KL contributed to data interpretation. LZ wrote the first draft of the manuscript which reviewed by KL. All authors contributed to revising the manuscript.

Funding KL was supported by the National Key Research and Development Programme of China (No.2018YFC1002304).

Competing interests None declared.

Patient consent for publication Not required.

Ethics approval Ethical approval was obtained from the Ethics Committee (Institutional Review Board, IRB) of Beijing Obstetrics and Gynaecology Hospital (No. 2019-KY-025-01).

Provenance and peer review Not commissioned; externally peer reviewed. Data availability statement № data are available.

Open access This is an open access article distributed in accordance with the Creative Commons Attribution Non Commercial (CC BY-NC 4.0) license, which permits others to distribute, remix, adapt, build upon this work non-commercially, and license their derivative works on different terms, provided the original work is properly cited, appropriate credit is given, any changes made indicated, and the use is non-commercial. See: http://creativecommons.org/licenses/by-nc/4.0/.

ORCID iD

Lu Zhang http://orcid.org/0000-0002-1716-7662

\section{REFERENCES}

1 Steptoe PC, Edwards RG. Birth after the reimplantation of a human embryo. Lancet 1978;2:366.

2 Kamel RM. Assisted reproductive technology after the birth of Louise brown. J Reprod Infertil 2013;14:96-109.

3 Gallagher J. Five millionth "test tube baby". BBC news, 2012 Available: http://www.bbc.co.uk/news/ health-18649582 [Accessed 15 Aug 2020].

4 Adamson GD, de Mouzon J, Chambers GM, et al. International Committee for monitoring assisted reproductive technology: world report on assisted reproductive technology, 2011. Fertil Steril 2018; $110: 1067-80$

5 Lab of Histoembryology and Reproductive Engineering in Beijing Medical University. China's first test-tube baby was born in Beijing Medical University (in Chinese). J Beijing Med Univ 1988;2:139.

6 Zhou Z, Chen L, Wu H, et al. Assisted reproductive technology in Beijing, 2013-2015. Reprod Biomed Online 2018;37:521-32.

7 Cavoretto PI, Farina A, Girardelli S, et al. Greater fetal crown-rump length growth with the use of in vitro fertilization or intracytoplasmic sperm injection conceptions after thawed versus fresh blastocyst transfers: secondary analysis of a prospective cohort study. Fertil Steril 2021;23. doi:10.1016/j.fertnstert.2020.11.035. [Epub ahead of print: 23 Jan 2021]

8 Cavoretto PI, Farina A, Gaeta G, et al. Uterine artery Doppler in singleton pregnancies conceived after in-vitro fertilization or intracytoplasmic sperm injection with fresh vs frozen blastocyst transfer: longitudinal cohort study. Ultrasound Obstet Gynecol 2020;56:603-10. 
9 Zhang WY, von Versen-Höynck F, Kapphahn KI, et al. Maternal and neonatal outcomes associated with trophectoderm biopsy. Fertil Steril 2019;112:283-90.

10 Riestenberg CK, Mok T, Ong JR, et al. Sonographic abnormalities in pregnancies conceived following IVF with and without preimplantation genetic testing for aneuploidy (PGT-A). J Assist Reprod Genet 2021;38:865-71.

11 Morin NC, Wirth FH, Johnson DH, et al. Congenital malformations and psychosocial development in children conceived by in vitro fertilization. J Pediatr 1989;115:222-7.

12 Rimm AA, Katayama AC, Diaz M, et al. A meta-analysis of controlled studies comparing major malformation rates in IVF and ICSI infants with naturally conceived children. J Assist Reprod Genet 2004;21:437-43.

13 Hansen M, Bower C, Milne E, et al. Assisted reproductive technologies and the risk of birth defects--a systematic review. Hum Reprod 2005;20:328-38.

14 McDonald SD, Murphy K, Beyene J, et al. Perinatel outcomes of singleton pregnancies achieved by in vitro fertilization: a systematic review and meta-analysis. J Obstet Gynaecol Can 2005;27:449-59.

15 Pandey S, Shetty A, Hamilton M, et al. Obstetric and perinatal outcomes in singleton pregnancies resulting from IVF/ICSI: a systematic review and meta-analysis. Hum Reprod Update 2012;18:485-503.

16 Wen J, Jiang J, Ding C, et al. Birth defects in children conceived by in vitro fertilization and intracytoplasmic sperm injection: a metaanalysis. Fertil Steril 2012;97:1331-7.

17 Hansen M, Kurinczuk JJ, Milne E, et al. Assisted reproductive technology and birth defects: a systematic review and meta-analysis. Hum Reprod Update 2013;19:330-53.

18 Davies MJ, Moore VM, Willson KJ, et al. Reproductive technologies and the risk of birth defects. N Engl J Med 2012;366:1803-13.

19 Boulet SL, Kirby RS, Reefhuis J, et al. Assisted reproductive technology and birth defects among Liveborn infants in Florida, Massachusetts, and Michigan, 2000-2010. JAMA Pediatr 2016;170:e154934.

20 Giorgione V, Parazzini F, Fesslova V, et al. Congenital heart defects in IVF/ICSI pregnancy: systematic review and meta-analysis. Ultrasound Obstet Gynecol 2018;51:33-42.

21 Yan J, Huang G, Sun Y, et al. Birth defects after assisted reproductive technologies in China: analysis of 15,405 offspring in seven centers (2004 to 2008). Fertil Steril 2011;95:458-60.

22 Lu Y-hong, Wang N, Jin F. Long-term follow-up of children conceived through assisted reproductive technology. J Zhejiang Univ Sci B 2013:14:359-71.

23 Yang M, Fan X-B, Wu J-N, et al. Association of assisted reproductive technology and multiple pregnancies with the risks of birth defects and stillbirth: a retrospective cohort study. Sci Rep 2018;8:8296.

24 Yu H-T, Yang Q, Sun X-X, et al. Association of birth defects with the mode of assisted reproductive technology in a Chinese data-linkage cohort. Fertil Steril 2018;109:849-56.

25 Lei L-L, Lan Y-L, Wang S-Y, et al. Perinatal complications and live-birth outcomes following assisted reproductive technology: a retrospective cohort study. Chin Med J 2019;132:2408-16.

26 Zhu J, Zhu Q, Wang Y, et al. Comparative study on risk for birth defects among infants after in vitro fertilization and intracytoplasmic sperm injection. Syst Biol Reprod Med 2019;65:54-60.

27 Sammel MD, Stentz N, Shah DK. Big data approach to evaluation of birth defects and assisted reproductive technology: the Chinese linkage cohort. Fertil Steril 2018;109:791-2.

28 WHO Expert Consultation. Appropriate body-mass index for Asian populations and its implications for policy and intervention strategies. Lancet 2004;363:157-63.

29 Xuequan M. China focus: Chinese mainland's 1st test-tube baby becomes mother. Xinhuanet News, 2019. Available: http://www. xinhuanet.com/english/2019-04/16/c_137979666.htm [Accessed 15 Aug 2020].

30 Sunderam S, Kissin DM, Zhang Y, et al. Assisted reproductive technology surveillance - United States, 2016. MMWR Surveill Summ 2019;68:1-23.

31 Sunderam S, Kissin DM, Crawford SB, et al. Assisted reproductive technology surveillance - United States, 2015. MMWR Surveill. Summ. 2018;67:1-28.
32 Sunderam S, Kissin DM, Crawford SB, et al. Assisted Reproductive Technology Surveillance - United States, 2014. MMWR Surveill Summ 2017;66:1-24.

33 Parazzini F, Cipriani S, Bulfoni G, et al. The risk of birth defects after assisted reproduction. J Assist Reprod Genet 2015;32:379-85.

34 Ooki S. Birth defects after assisted reproductive technology according to the method of treatment in Japan: nationwide data between 2004 and 2012. Environ Health Prev Med 2015;20:460-5.

35 Luke B, Gopal D, Cabral H, et al. Pregnancy, birth, and infant outcomes by maternal fertility status: the Massachusetts outcomes study of assisted reproductive technology. Am J Obstet Gynecol 2017;217:327.e1-327.e14.

36 Simpson JL. Birth defects and assisted reproductive technologies. Semin Fetal Neonatal Med 2014;19:177-82.

37 Hansen M, Bower C. The impact of assisted reproductive technologies on intra-uterine growth and birth defects in singletons. Semin Fetal Neonatal Med 2014;19:228-33.

38 Davies MJ, Rumbold AR, Marino JL, et al. Maternal factors and the risk of birth defects after IVF and ICSI: a whole of population cohort study. BJOG 2017;124:1537-44.

39 Luke B. Pregnancy and birth outcomes in couples with infertility with and without assisted reproductive technology: with an emphasis on US population-based studies. Am J Obstet Gynecol 2017;217:270-81.

40 Dai L, Zhu J, Liang J, et al. Birth defects surveillance in China. World $J$ Pediatr 2011;7:302-10.

41 Ministry of Health of China, China Disabled Persons' Federation. China action to improve constitution of birth population quality and reduce birth defects and disabilities (2002-2010)(in Chinese). Zhongguo Sheng Yu Jian Kang Za Zhi 2002;13.

42 Dawson AL, Tinker SC, Jamieson DJ, et al. Twinning and major birth defects, National birth defects prevention study, 1997-2007. J Epidemiol Community Health 2016;70:1114-21.

43 Jung JH, Graham JM, Schultz N, et al. Congenital hydranencephaly/ porencephaly due to vascular disruption in monozygotic twins. Pediatrics 1984;73:467-9.

44 Källén B. Congenital malformations in twins: a population study. Acta Genet Med Gemellol 1986;35:167-78.

45 Hay S, Wehrung DA. Congenital malformations in twins. Am J Hum Genet 1970;22:662-78.

46 Zhu JL, Basso O, Obel C, et al. Infertility, infertility treatment, and congenital malformations: Danish national birth cohort. BMJ 2006;333:679.

47 Hollier LM, Leveno KJ, Kelly MA, et al. Maternal age and malformations in singleton births. Obstet Gynecol 2000;96:701-6.

48 Cavoretto P, Candiani M, Giorgione V, et al. Risk of spontaneous preterm birth in singleton pregnancies conceived after IVF/ICSI treatment: meta-analysis of cohort studies. Ultrasound Obstet Gynecol 2018;51:43-53.

49 Cavoretto P, Giorgione V, Cipriani S, et al. Nuchal translucency measurement, free $\beta-h C G$ and PAPP-A concentrations in IVF/ICSI pregnancies: systematic review and meta-analysis. Prenat Diagn 2017:37:540-55

50 Fantasia I, Kasapoglu D, Kasapoglu T, et al. Fetal major cardiac defects and placental dysfunction at 11-13 weeks' gestation. Ultrasound Obstet Gynecol 2018;51:194-8.

51 Thilaganathan B. Preeclampsia and fetal congenital heart defects: spurious association or maternal confounding? Circulation 2017:136:49-51.

52 Maheshwari A, Pandey S, Amalraj Raja E, et al. Is frozen embryo transfer better for mothers and babies? can cumulative metaanalysis provide a definitive answer? Hum Reprod Update 2018;24:35-58.

53 Oldereid NB, Wennerholm U-B, Pinborg A, et al. The effect of paternal factors on perinatal and paediatric outcomes: a systematic review and meta-analysis. Hum Reprod Update 2018;24:320-89.

54 Nybo Andersen A-M, Urhoj SK. Is advanced paternal age a health risk for the offspring? Fertil Steril 2017;107:312-8.

55 Liberman RF, Getz KD, Heinke D, et al. Assisted reproductive technology and birth defects: effects of subfertility and multiple births. Birth Defects Res 2017;109:1144-53.

56 Tararbit K, Lelong N, Houyel L, et al. Assessing the role of multiple pregnancies in the association between tetralogy of Fallot and assisted reproductive techniques: a path-analysis approach. Orphanet J Rare Dis 2014;9:27. 